\title{
Growth of Acropora formosa Fragments in In-situ Coral Nurseries at Polhena Reef, Matara, Sri Lanka \\ C. Siriwardhana ${ }^{*}$, R.R.M.K.P Ranatunga \\ Department of Zoology, University of Sri Jayewardenepura, Sri Lanka \\ *chamika888@gmail.com
}

\begin{abstract}
Coral reef are one of the most valuable coastal ecosystems, yet they are under various threats. Present study was to investigate the growth of Acropora Formosa fragments in in-situ coral nurseries of Matara Pollhena reef located on the southern coast of Sri Lanka.

Study was conducted between April to November 2014. Eight different sites representing open sea and reef lagoon were selected to compare growth of $A$. formosa fragments in coral nurseries. Seawater quality parameters such as salinity, water temperature, $\mathrm{pH}$, dissolved oxygen, nitrates, and phosphates were measured in monthly intervals. In addition, sedimentation rate was determined by deploying sediment traps.

The highest mean extension growth rate for A. formosa $(1.07 \pm 0.05 \mathrm{~cm}$ per month) was recorded at a site in the reef lagoon close to Nilwala river out fall and lowest mean extension rate $(0.20 \pm 0.06 \mathrm{~cm}$ per month) was also recorded in reef lagoon more southward to the Nilwala river outfall. There was significantly different growth rates among eight sampling sites $(t$-test, $\mathrm{p}<0.05)$. The mean extension growth rates for open sea sites were higher when compared with reef lagoon sites $(0.41 \pm 0.09 \mathrm{~cm}$ per month, $0.72 \pm 0.07 \mathrm{~cm}$ per month) respectively. The survival rates of coral fragments were ranged from $85.71 \%$ to $65.08 \%$. The results highlight that the $A$. formosa shows differential growth rates in reef lagoon and open sea areas. Further, A. formosa has higher growth rate compared to other coral species and also can withstand higher sedimentation rates.
\end{abstract}

Keywords: Acropora formosa, Coral growth, Coral nurseries, Polhena reef 